\title{
Roles of the Telencephalic Cells and their Chondroitin Sulfate Proteoglycans in Delimiting an Anterior Border of the Retinal Pathway
}

\author{
Hiroyuki Ichijo and Izumi Kawabata \\ Department of Anatomy, Institute of Basic Medical Sciences, University of Tsukuba, Tsukuba, Ibaraki 305-8575, Japan
}

The axons of the retinal ganglion cells run on the diencephalotelencephalic boundary on their way to the tectum; however, they do not invade the telencephalon anteriorly. To investigate the mechanisms that prevent the retinal axons from entering the telencephalic territory, the effects of the telencephalic cells were examined on the outgrowth of the retinal axons in vitro; the retinal outgrowth was selectively inhibited by the cellular substrate derived from the telencephalon. The responsible factor for the selective inhibition was, furthermore, found in the telencephalic membranes and the fraction of peripheral membrane molecules from the telencephalon. Because the inhibitory effect was destroyed by chondroitinase $A B C$ but not by heat, this inhibition was attributable to the carbohydrate chains

Neurons extend their axons through a precise and stereotyped pathway and project to their target during development. The formation of neuronal circuits is one of the important problems in developmental neurobiology, which is the structural basis of brain functions (Goodman, 1996; Tessier-Lavigne and Goodman, 1996). Retinotectal projections have long served as a good model for the formation of neuronal circuits (Holt and Harris, 1993; Dingwell et al., 2000; Mey and Thanos, 2000).

It is shown that sequential presentation of guidance cues directs the retinal axons to their final target (Karlstrom et al., 1996; Trowe et al., 1996). Retinal ganglion cells (RGCs) extend their axons to the center of retina; lens epithelial cells secret a repulsive factor and are likely to initially direct the retinal axons to the central retina (Ohta et al., 1999). Furthermore, because chondroitin sulfate proteoglycans (CSPGs) are expressed in a decreasing gradient from the retinal periphery to its center and inhibit the growth of the retinal axons, they are also likely to direct the axonal growth to the central retina (Snow et al., 1991; Brittis et al., 1992). The retinal axons turn their direction at the optic nerve head and exit the eyeball; their turning is thought to be induced by Netrin-1 (Deiner et al., 1997). The retinal axons form the optic chiasm at the ventral midline of the diencephalon (Guillery et al., 1995; Mason and Sretavan, 1997); it has been reported that

Received May 17, 2001; revised Aug. 7, 2001; accepted Sept. 4, 2001.

This work was supported by Grants-in-Aid for Scientific Research on Priority Areas (C)-Advanced Brain Science Project from the Ministry of Education, Culture, Sports, Science, and Technology, Japan, for the Basic Science Research from the Sumitomo Foundation in Tokyo, Japan, and for the Research Projects from University of Tsukuba in Tsukuba, Japan. We thank N. Sugae for her technical assistance and Prof. S. Hisano for encouragement.

Correspondence should be addressed to Hiroyuki Ichijo, Department of Anatomy, Institute of Basic Medical Sciences, University of Tsukuba, Tsukuba, Ibaraki 305-8575, Japan. E-mail: ichijo@md.tsukuba.ac.jp.

Copyright (C) 2001 Society for Neuroscience $0270-6474 / 01 / 219304-11 \$ 15.00 / 0$ of chondroitin sulfate proteoglycans (CSPGs) adhering to the membranes of the telencephalic cells. To understand the function of the telencephalic CSPGs on the retinal pathfinding in vivo, their carbohydrate chains [chondroitin sulfate glycosaminoglycan (CS-GAG)] were removed from the embryonic brains by intraventricular injection of chondroitinase $A B C$; the removal of CS-GAG resulted in an anterior enlargement of the optic tract. The results indicate that the telencephalic cells delimit the anterior border of the optic tract with their CSPGs and prevent the retinal axons from aberrantly entering the anterior territory.

Key words: axon guidance; pathfinding; retinotectal projection; optic tract; retinal ganglion cell; chondroitin sulfate proteoglycan; telencephalon
Ephrin-As, Ephrin-Bs, Netrin-1, Slit-2, and CSPGs are involved in the formation of the optic chiasm (Deiner and Sretavan, 1999; Dutting et al., 1999; Chung et al., 2000a,b; Erskine et al., 2000; Marcus et al., 2000; Nakagawa et al., 2000; Niclou et al., 2000). The retinal axons run dorsocaudally in the middle part of the diencephalon; they are guided by an early-generated axonal scaffold, the tract of the postoptic commissure (Wilson et al., 1990; Taylor, 1991; Easter et al., 1993; Chedotal et al., 1995; Mastick and Easter, 1996; Anderson and Key, 1999). In addition, the carbohydrate chains of heparan sulfate proteoglycans regulate the guidance of the retinal axon in the diencephalon through their binding to fibroblast growth factors (Walz et al., 1997). In contrast, the retinal axons do not invade the dorsal and ventral diencephalon during early development, in which Slit-2 is expressed. Because Slit-2 repels the retinal axons in vitro, this suggests that Slit-2 prevents the retinal axons from invading the dorsal and ventral diencephalon (Tuttle et al., 1998; Erskine et al., 2000; Niclou et al., 2000; Ringstedt et al., 2000).

On their way to the tectum, the retinal axons run on the diencephalotelencephalic boundary and cross over the supraoptic tract (SOT), which is another axonal scaffold between the telencephalon and diencephalon, but they do not invade the telencephalon anteriorly (see Fig. 1). Among the zebrafish mutants, five mutants (bal, gup, sly, cyc, and ast) show retinal axons that turn anteriorly and aberrantly invade the telencephalon (Karlstrom et al., 1996). In addition, at the border between the telencephalon and diencephalon, there is a region with a dense cluster of non-neuronal cells, which may function as a barrier that prevents the retinal axons from invading the telencephalon (Silver et al., 1987). These observations indicate the mechanisms that prevent the retinal axons from aberrantly invading the telencephalon; however, their cellular and molecular bases have not been elucidated. 

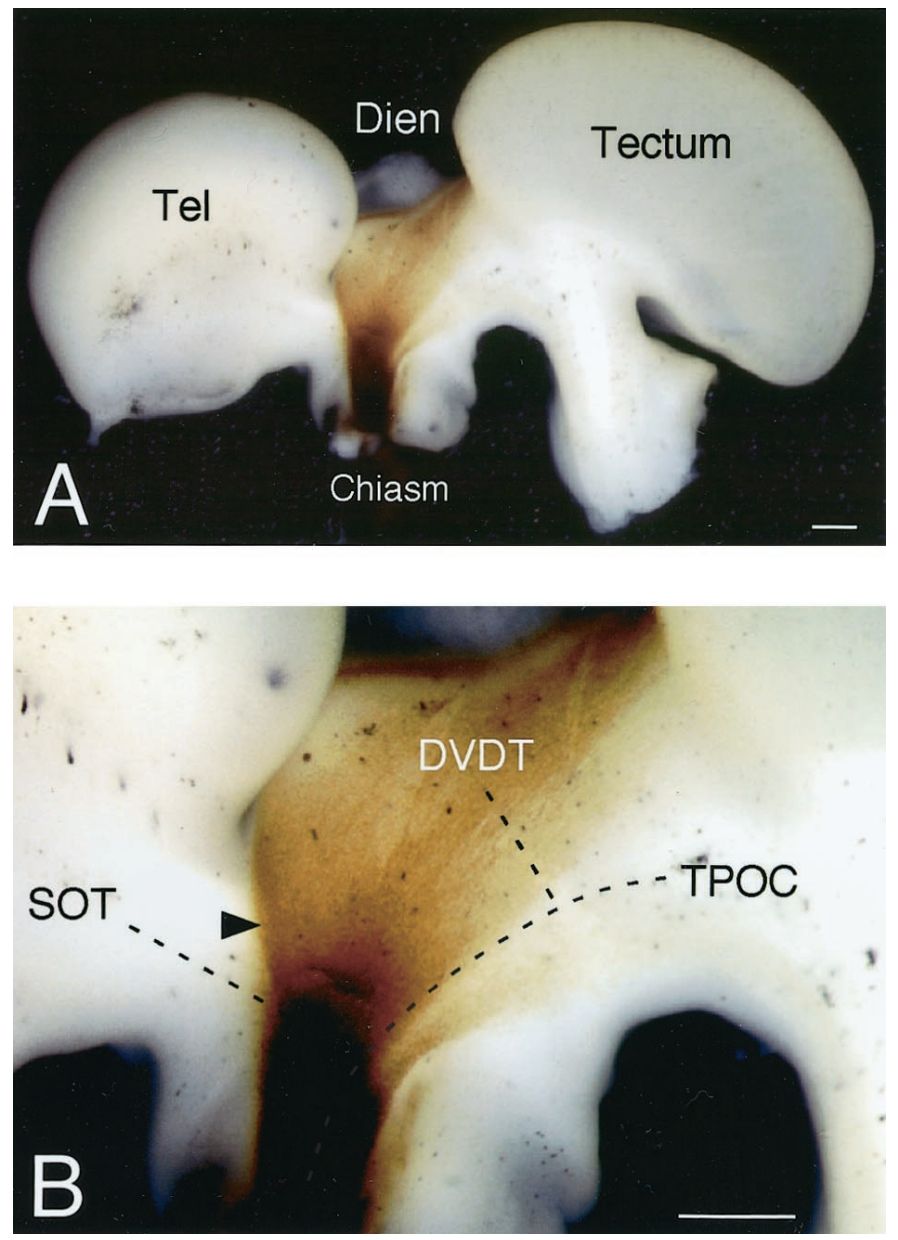

Figure 1. Axonal trajectories of the retinal ganglion cells of E7 chickens. $A$, The retinal axons run on the diencephalon dorsocaudally to the tectum. Chiasm, Optic chiasm; Dien, diencephalon; Tectum, optic tectum; Tel, telencephalon. $B$, In the anterior diencephalon, they run on the diencephalotelencephalic boundary (arrowhead) but do not enter the telencephalic territory. Positions of the following axonal scaffolds are indicated: DVDT, the dorsoventral diencephalic tract; TPOC, the tract of the postoptic commissure; SOT, the supraoptic tract. Scale bars, $50 \mu \mathrm{m}$.

To understand the mechanisms that prevent the retinal axons from invading the telencephalon, the effects of telencephalic cells were examined on outgrowth of the retinal axons in vitro with a coculture method devised previously, the ryomen chamber assay (Ichijo and Bonhoeffer, 1998). Here we show in the chick embryo that (1) the retinal outgrowth was selectively inhibited by the telencephalic cells, (2) CSPGs adhering to the telencephalic membranes selectively inhibited the outgrowth of the retinal axons in vitro via their carbohydrate chains [chondroitin sulfate glycosaminoglycans (CS-GAGs)], and (3) removal of the CSGAGs by enzymatic treatment induced an anterior enlargement of the optic tract toward the telencephalon in vivo. The results indicate that the telencephalic cells delimit the anterior border of the optic tract by their CSPGs.

\section{MATERIALS AND METHODS}

The ryomen chamber assay. The coculture assay, the ryomen chamber assay, was developed by Ichijo and Bonhoeffer (1998) to inspect interactions between the RGC axons and the processes of their target cells, mediated through either contact or diffusion; this assay was applied to investigating the pathfinding of retinal axons (Fig. 1). "Ryomen" is the Japanese term for "double-sided." The chamber consisted of a pair of
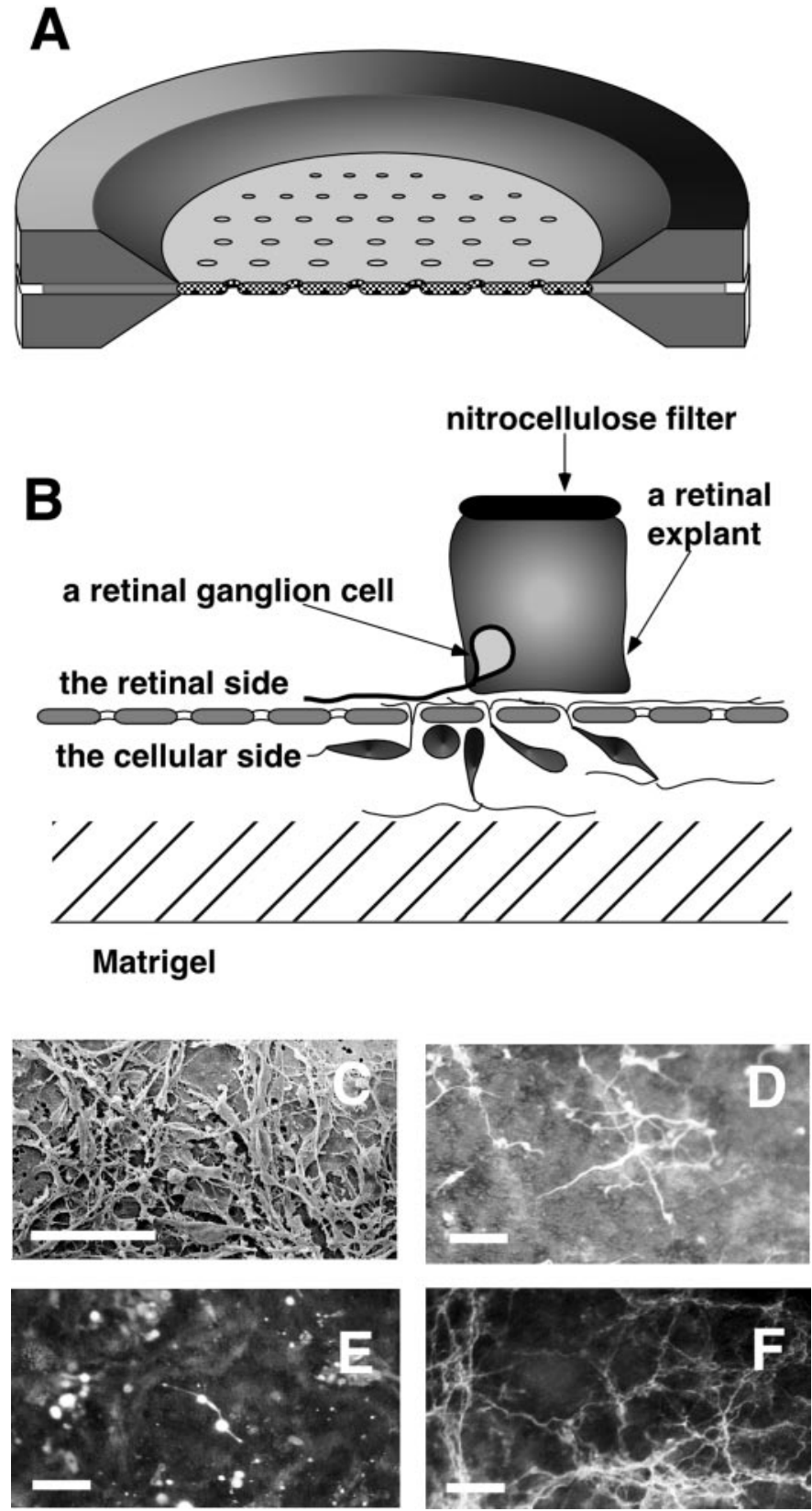

Figure 2. Schematic drawings of the experiments in the ryomen chamber and the telencephalic substrates. $A$, A pair of stainless steel rings holds the Nuclepore filter. $B$, An axon of a retinal ganglion cell grows on the processes of telencephalic cells that have penetrated the filter. $C$, A scanning electron micrograph shows the telencephalic substrate on the retinal side of the filter. The telencephalic substrates consist of cellular processes that are positive for MAP2 $(D)$, vimentin $(E)$, and G4/NgCAM $(F)$. Scale bars, $25 \mu \mathrm{m}$.

stainless steel rings holding the Nuclepore filter (Fig. $2 A, B$ ). The inner and outer diameters of the rings were 10 and $50 \mathrm{~mm}$, respectively. The Nuclepore filter with pores of $1.0 \mu \mathrm{m}$ in diameter was treated overnight at $37.5^{\circ} \mathrm{C}$ with a diluted Matrigel (Becton Dickinson, Bedford, MA) solution containing $1 \mathrm{mg} / \mathrm{ml}$ total protein in HBSS. The filter was inserted between the rings and sealed with silicone paste. One side of the filter, the cellular side, was used for culturing telencephalic cells; the other side, the retinal side, served for the growth of retinal axons.

Fertilized chicken eggs were obtained from a local farm. They were incubated at $37^{\circ} \mathrm{C}$. Telencephalons and anterior thirds of optic tecta were dissected from embryonic day 6 (E6) or E8 chickens in ice-cold HBSS. The tissues were cut in pieces in the HBSS and subsequently treated with 
a trypsin-EDTA solution (Sigma, St. Louis, MO) for $10 \mathrm{~min}$ at $37.5^{\circ} \mathrm{C}$. Trypsinization was stopped by adding fetal bovine serum. Cell suspensions were prepared by trituration and washed twice in an F-12 culture medium consisting of an F-12 nutrient mixture, $10 \%$ fetal bovine serum, $2 \%$ chick serum, $2 \mathrm{~mm}$ glutamine, and penicillin-streptomycin (all reagents in the F-12 culture medium were from Life Technologies, Rockville, MD). Five hundred microliters of the cell suspensions $\left(1.0 \times 10^{7}\right.$ cells $/ \mathrm{ml}$ ) were cultured on the cellular side of the filter overnight at $37.5^{\circ} \mathrm{C}$ in $4 \% \mathrm{CO}_{2}$. The next day, the cultured media were removed; then, $25 \mu \mathrm{l}$ of Matrigel were added to the tectal side. After incubation for 30 min at $37.5^{\circ} \mathrm{C}$ in $4 \% \mathrm{CO}_{2}$, the chambers were turned upside down to make the other side, the retinal side, of the filter available. The recovered media were centrifuged to remove cellular debris and mixed with the same volume of fresh F-12 culture medium.

Neural retinas from E6 or E7 chickens were prepared (Halfter et al., 1983). The retina was chopped perpendicular to the optic fissure with a tissue chopper (The Mickle Laboratory Engineering, Gomshall, UK) to make 0.3 -mm-wide retinal strips. The explants $(0.3 \times 0.6 \mathrm{~mm})$ were obtained from the central part of the retina for the experiments. Dorsal root ganglia (DRGs) were also prepared from E7 chickens. The retinal and DRG explants were placed on the retinal side of the filter immediately after the filter had been turned upside down. Nine hundred microliters of medium, the mixture of the cultured and fresh medium, were added to each culture; then, they were cultured for 3 more days. The retinal explants and telencephalic cells were cultured on the two sides of a filter, which allowed both contact- and diffusion-mediated interactions; the retinal axons contacted the cellular processes derived from the telencephalic cells that penetrate the filter pores, and the retinal axons were also influenced by a soluble factor secreted from the telencephalic cellular processes.

Immunocytochemistry and scanning electron microscopy. The cultures were fixed with $4 \%$ paraformaldehyde (PFA) in PBS overnight at room temperature. The retinal axons were stained as whole mounts with an antibody against G4/NgCAM (Rager et al., 1996). The cultures were also stained with antibodies against microtubule-associated protein-2 (MAP2) (Sigma), vimentin (Boehringer Mannheim, Mannheim, Germany), and glial fibrillary acidic protein (GFAP) (Sigma). They were subsequently incubated with the appropriate Cy3-coupled secondary antibodies (Jackson ImmunoResearch, West Grove, PA) and then examined and photographed under a fluorescence microscope (Zeiss, Oberkochen, Germany). The images were digitized with a film scanner (Nikon, Tokyo, Japan). By using NIH Image software (version 1.60; Wayne Rasband, National Institutes of Health, Bethesda, MD), diameters of axonal halo were measured on the cellular substrates because the retinal and DRG axons grow radially from the explants. The data were expressed as the mean $\pm \mathrm{SE}$; they were analyzed with an unpaired $t$ test.

For scanning electron microscopy, the telencephalic substrates were fixed with $4 \%$ PFA in PBS overnight at $4^{\circ} \mathrm{C}$ and with $2.5 \%$ glutaraldehyde in PBS for $1 \mathrm{hr}$ on ice. Then, they were post-fixed with $1 \% \mathrm{OsO}_{4}$ in PBS for $1 \mathrm{hr}$ on ice and stained with $1 \%$ uranyl acetate for $1 \mathrm{hr}$. Finally, they were dehydrated, critical point-dried, and coated with gold and palladium.

Retinal explant cultures in conditioned media, with membrane fractions, and with peripheral membrane molecules. Conditioned media were recovered from the ryomen chamber culture with no retinal explant at the third day and centrifuged twice at $150,000 \times g$ for $10 \mathrm{~min}$ at $4^{\circ} \mathrm{C}$ to remove cell membranes. Because crude conditioned media contained low molecular weight metabolites that might nonspecifically inhibit axon outgrowth, the media were freed of low molecular weight components by ultrafiltration (Ichijo and Bonhoeffer, 1998); they were concentrated with Centrisart I microconcentrators $(5 \mathrm{kDa}$ exclusion limit; Sartorius, Goettingen, Germany) and brought to the original volume with F-12 minimum medium (F-12 nutrient mixture and $2 \mathrm{~mm}$ L-glutamine). For heat treatment, medium conditioned by the E8 telencephalic cells for $3 \mathrm{~d}$ was heated to $63^{\circ} \mathrm{C}$ for $8 \mathrm{~min}$ after being concentrated, and it was brought to the original volume with F-12 minimum medium. The retinal explants $(0.3 \times$ $0.6 \mathrm{~mm}$ ) from the central part of the retina and DRG explants were cultured for $40 \mathrm{hr}$ in $300 \mu \mathrm{l}$ of the conditioned media on a thin layer of Matrigel.

Telencephalons or anterior tecta from E8 or E13 chickens were homogenized in homogenization buffer [ $25 \mathrm{~mm}$ Tris- $\mathrm{HCl}$, $\mathrm{pH} 7.5$, with a protease inhibitor cocktail (complete mini; Roche Molecular Biochemicals, Mannheim, Germany)]. The homogenates were centrifuged at $8000 \times g$ for $10 \mathrm{~min}$ at $4^{\circ} \mathrm{C}$ to remove unbroken cells and organelles. Membranes were pelleted at $150,000 \times g$ for $10 \mathrm{~min}$ at $4^{\circ} \mathrm{C}$. The membranes were treated with heat $\left(100^{\circ} \mathrm{C}\right.$ for $\left.5 \mathrm{~min}\right)$, keratanase $(0.5$ $\mathrm{U} / \mathrm{mg}$ protein at $37^{\circ} \mathrm{C}$ for $1 \mathrm{hr}$; Seikagaku Corporation, Tokyo, Japan), or chondroitinase $\mathrm{ABC}\left(0.5 \mathrm{U} / \mathrm{mg}\right.$ protein at $37^{\circ} \mathrm{C}$ for $1 \mathrm{hr}$; Seikagaku Corporation). These membranes were washed with PBS; then, they were suspended in the F-12 minimum medium $(0.5 \mathrm{mg} / \mathrm{ml}$ protein). In $300 \mu \mathrm{l}$ of these media, the retinal and DRG explants were cultured for $24 \mathrm{hr}$.

To separate peripheral membrane molecules from the integral ones, the membranes were phase-partitioned with Triton X-114 (Brusca and Radolf, 1994; Nomura et al., 1998). The membranes were dissolved in $2 \%$ Triton X-114 (Sigma) in the homogenization buffer $(1 \mathrm{ml} / \mathrm{mg}$ protein) and extracted overnight at $4^{\circ} \mathrm{C}$. The solutions were incubated at $37^{\circ} \mathrm{C}$ for $10 \mathrm{~min}$ and centrifuged at $16,000 \times g$ for $10 \mathrm{~min}$ at $25^{\circ} \mathrm{C}$. After the centrifugation, peripheral and integral membrane molecules were concentrated in an upper aqueous and a lower detergent phase, respectively. The upper aqueous phases were recovered and treated with Bio-Beads SM-2 (Bio-Rad, Hercules, CA) with gentle rotation for $1 \mathrm{hr}$ at $37^{\circ} \mathrm{C}$ to remove the detergent that remained in the samples (Levy et al., 1990); then, the samples were concentrated with the Centrisart I microconcentrators. The retinal and DRG explants were cultured for $24 \mathrm{hr}$ in $300 \mu \mathrm{l}$ of the F-12 minimum medium with the peripheral membrane molecules $(0.5 \mathrm{mg} / \mathrm{ml}$ protein).

In the experiments with the conditioned media, the cultures were fixed and stained immunofluorescently with the anti-G4/NgCAM antibody. In the experiments with the membrane fractions, they were observed under a phase-contrast microscope (Nikon) because the G4/NgCAM immunoreactivity was so intense in the membranes that it disturbed the observation of the retinal axons; in the experiments with the peripheral membrane molecules, they were also observed under the phase-contrast microscope. They were photographed, and their images were digitized with the film scanner. By using NIH Image software, pixels over axonal bundles were counted, but those over the explant itself or migrated cells were neglected, and the total areas covered with the axonal bundles were calculated (in square millimeters). The data were expressed as the mean $\pm \mathrm{SE}$; they were analyzed with an unpaired $t$ test.

Enzymatic removal of the chondroitin sulfate by injecting chondroitinase $A B C$ into the lateral ventricle. The fertilized chicken eggs were incubated at $37^{\circ} \mathrm{C}$. A window was opened on the eggshells at E2. On E6, a small hole was made over the right telencephalon with a sharp tungsten needle. Through the hole, a glass micropipette was inserted into the right lateral ventricle, and $\sim 5 \mu \mathrm{l}$ of a $1 \mu \mathrm{U} / \mu \mathrm{l}$ solution of chondroitinase ABC in PBS was injected with a microinjector (Narishige, Tokyo, Japan). As negative controls, a chondroitinase $\mathrm{ABC}$ solution boiled for 5 min or PBS was injected.

To verify effects of the chondroitinase ABC on removal of CS-GAG, the distribution of CS-GAG was examined by immunohistochemistry. After a survival period of $\sim 24 \mathrm{hr}$, the embryos were dissected, and their brains and retinas were fixed with $3.7 \%$ formaldehyde in PBS at $4^{\circ} \mathrm{C}$ overnight. They were immersed overnight in $30 \%$ sucrose in PBS, embedded in the OCT compound (Sakura Finetechnical Co., Tokyo, Japan), and sectioned horizontally in $10 \mu \mathrm{m}$ thickness with a cryostat (Leica, Nussloch, Germany). The sections were blocked with $10 \%$ normal goat serum in PBS and incubated overnight at $4{ }^{\circ} \mathrm{C}$ in primary antibody CS-56 (Sigma) with $0.5 \%$ Triton X-100 in PBS. After several rinses in PBS, the sections were incubated with Cy3-coupled secondary antibodies (Jackson ImmunoResearch), examined, and photographed under a fluorescence microscope (Zeiss).

Labeling of the retinal axons with horseradish peroxidase. Immediately after the injection of chondroitinase ABC, a small hole was made on the left sclera with the tungsten needle. Another glass micropipette was inserted into the left eyeball through the hole, and $\sim 2.5 \mu \mathrm{l}$ of a $25 \%(\mathrm{w} / \mathrm{v})$ solution of horseradish peroxidase (HRP) (Toyobo, Tokyo, Japan) was injected with the microinjector (Thanos et al., 1984; Fujisawa, 1987). After a survival period of $\sim 24 \mathrm{hr}$, these embryos were dissected, and their brains were fixed with $3 \%$ glutaraldehyde in PBS at $4^{\circ} \mathrm{C}$ for a few hours. They were washed twice in PBS, treated with $0.3 \%$ Triton X-100 and $10 \%$ sucrose in PBS, and reacted with a working solution of the metal enhanced DAB substrate kit (Pierce, Rockford, IL) to visualize axons of the retinal ganglion cells. They were photographed under a dissection microscope (Nikon). They were, subsequently, embedded in $2 \%$ low-melting point agarose (Wako, Osaka, Japan) and sectioned to a thickness of $100 \mu \mathrm{m}$ with the Vibratome (TPI Vibratome, St. Louis, MO). The sections were stained with 4',6'-diamidino-2-phenylindole (DAPI) and photographed by Nomarski and epifluorescence optics (Zeiss). Their images were analyzed with NIH Image software; distances were measured between the most anteriorly situated retinal axon 

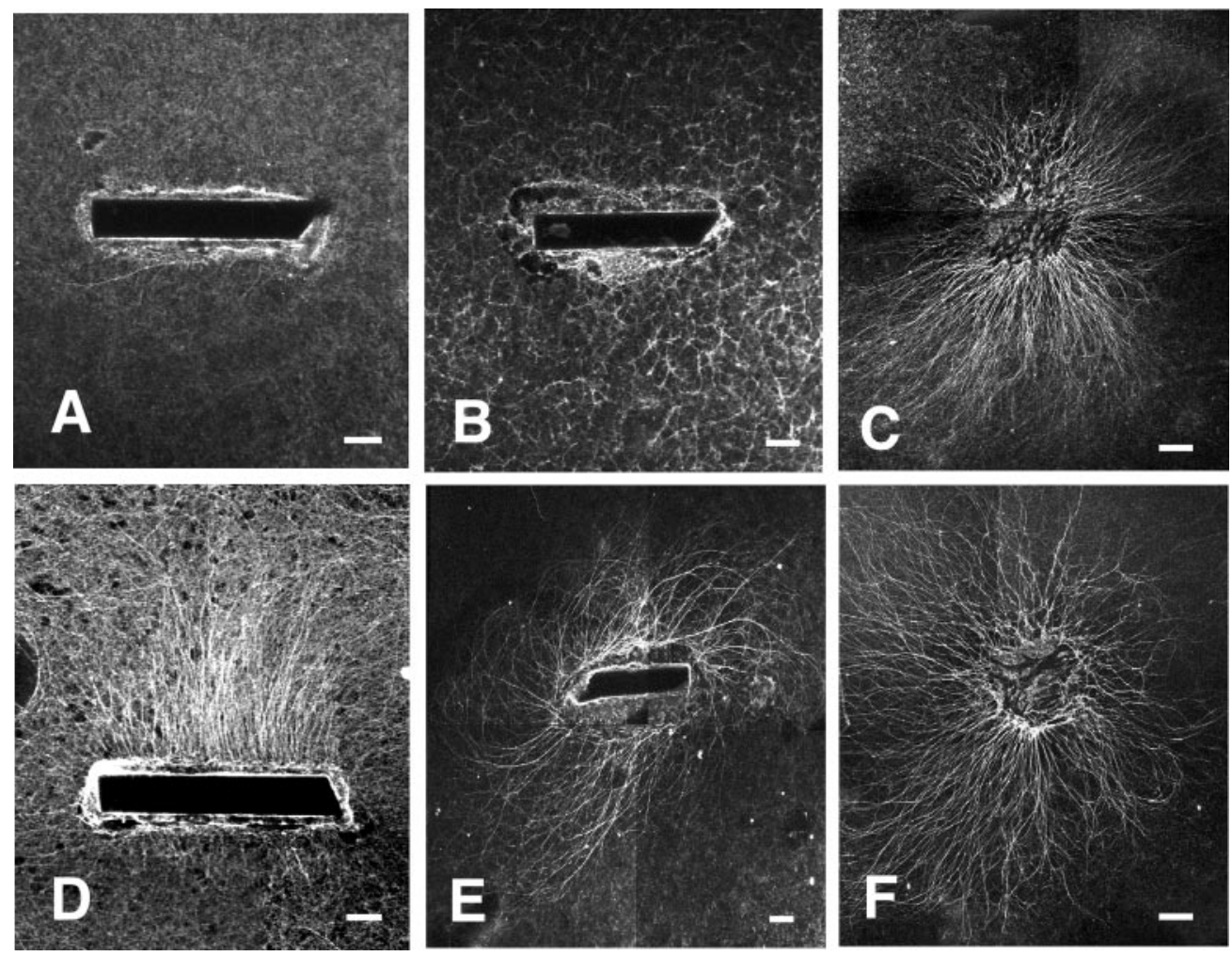

and the groove above the thin layer of cells on the SOT, the diencephalotelencephalic boundary. The data were expressed as the mean $\pm \mathrm{SE}$ and compared with an unpaired $t$ test.

\section{RESULTS}

\section{The telencephalic substrate consists of cellular processes of various origins}

Cells from the E8 telencephalon were cultured overnight on one side of the Nuclepore filter (the cellular side) in the ryomen chamber (Fig. 2B); the next day, the chamber was turned upside down. Processes from the telencephalic cells penetrated the filter to generate a cellular substrate on the side of the filter opposite to their cell bodies (the retinal side). This telencephalic substrate consisted of three types of processes: thin, flat, and round ones (Fig. $2 C$ ). The round processes were $5-10 \mu \mathrm{m}$ in diameter. The expression of the following cell-type markers was examined with immunocytochemistry: MAP2 for neuronal dendrites (Fig. 2D), G4/NgCAM for axons (Fig. $2 F$ ), GFAP for mature astrocytic processes (data not shown), and vimentin for immature glial processes (Fig. 2E). The elongated and flat processes were mainly neuronal, based on MAP2 and G4/NgCAM immunoreactivity. The round processes showed vimentin immunoreactivity. No processes were immunopositive for GFAP. The results showed the presence of both neuronal and immature glial processes in the substrate after $3 \mathrm{~d}$ in vitro.

\section{Differential outgrowth of the retinal axons on the cellular substrates}

The retinal axons grew well on the anterior tectal substrates (Fig. $3 D, E$ ) and intermediately on the diencephalic substrates (picture not shown; see Fig. $6 A$ ) ; however, the axons from the central, nasal, or temporal retina did not grow on the telencephalic substrates (Fig. $3 A, B$ ). To quantify the axonal outgrowth, the diameters of the axonal halos radiating from the retinal explants were measured; it was not feasible to calculate total areas covered

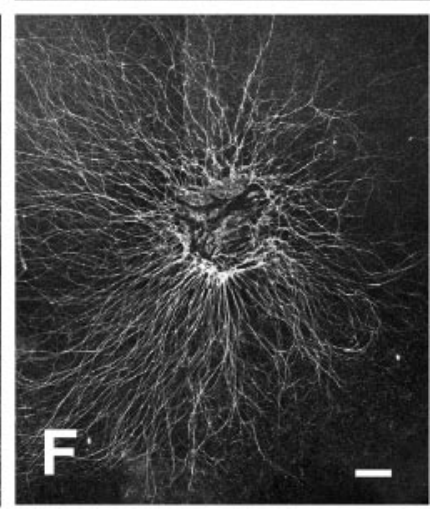

Figure 3. Axonal outgrowth on the substrates in the ryomen chambers. The axons are observed from the retinal side of the filter after $3 \mathrm{~d}$. The black areas in the middle of the pictures are the nitrocellulose filters that mechanically support the retinal tissues $(A, B, D, E)$. Few retinal axons grow on the E6 $(A)$ and E8 $(B)$ telencephalic substrates, although they grow well on the E6 $(D)$ and E8 $(E)$ anterior tectal substrates. The DRG axons grow well on either the E8 telencephalic substrate $(C)$ or E8 anterior tectal substrate $(F)$. Scale bars, $300 \mu \mathrm{m}$.

with axonal bundles from an explant because the neurites were stained by G4/NgCAM in the cellular substrates (Fig. $2 F$ ). The diameters of axonal halos were significantly smaller on the telencephalic substrates than on the anterior tectal substrates $[1.4 \pm$ $0.1 \mathrm{~mm}$ on the E6 telencephalic substrates $(n=11) ; 3.6 \pm 0.3 \mathrm{~mm}$ on the E6 anterior tectal substrates $(n=11) ; p<0.0001][1.4 \pm$ $0.1 \mathrm{~mm}$ on the E8 telencephalic substrates $(n=52) ; 3.8 \pm 0.2 \mathrm{~mm}$ on the E8 anterior tectal substrates $(n=67) ; p<0.0001$ ] (see Fig. $6 A$ ). The DRG axons grew well on either the telencephalic or anterior tectal substrates (Fig. 3C,F).

\section{A factor inhibiting the outgrowth of retinal axons in the medium conditioned by the telencephalic cells}

To characterize the effect of the telencephalic substrates on the outgrowth of the retinal axons, the retinal and DRG explants were cultured in media conditioned by the anterior tectal or telencephalic cells. The retinal axons grew profusely in the F-12 culture medium and the media conditioned by anterior tectal cells (Fig. 4A,B); however, they did not grow in the medium conditioned by telencephalic cells (Fig. $4 C$ ). With respect to the total area covered with axonal bundles from an explant, which is comparable with the product between the number and length of the axons, the outgrowth in the medium conditioned by telencephalic cells $\left[0.22 \pm 0.03 \mathrm{~mm}^{2}(n=33)\right]$ was $53 \%$ of that in the medium conditioned by anterior tectal cells $\left[0.42 \pm 0.03 \mathrm{~mm}^{2}\right.$ $(n=14)](p<0.0001)$ (see Fig. $6 B)$; the outgrowth of retinal axons in the medium conditioned by telencephalic cells was significantly less than that in the medium conditioned by anterior tectal cells. In contrast, the DRG axons grew equally well in the F-12 culture medium and the medium conditioned by anterior tectal cells or by telencephalic cells (Fig. $4 E-G$ ).

In the case in which the medium conditioned by telencephalic cells was heat treated, the retinal axons did not grow well either; only small numbers of thin axonal bundles were highly fascicu- 

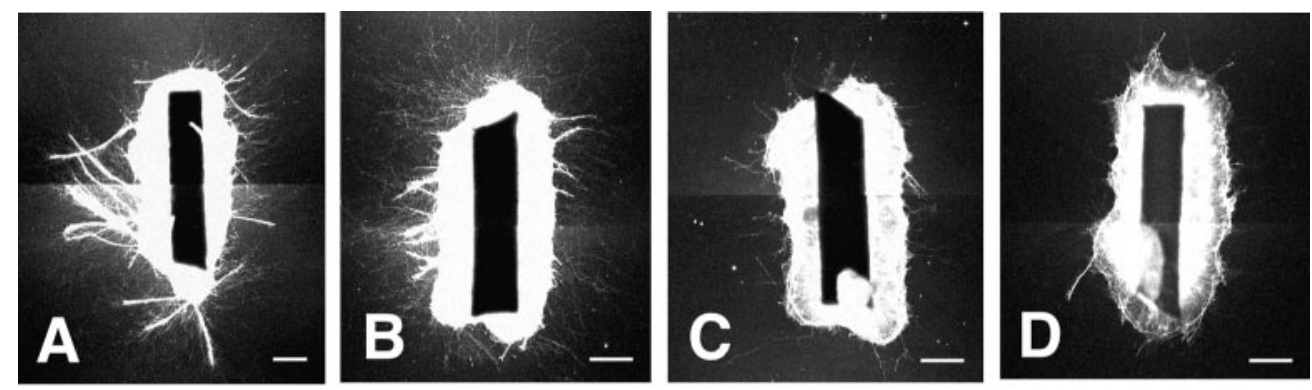

Figure 4. Axonal outgrowth in the conditioned media. The retinal $(A-D)$ and DRG $(E-H)$ explants are cultured in the F-12 culture medium $(A, E)$, in the medium conditioned by the $\mathrm{E} 8$ anterior tectal cells $(B, F)$, in the medium conditioned by the E8 telencephalic cells $(C, G)$, and in the heattreated medium conditioned by the $\mathrm{E} 8$ telencephalic cells $(D, H)$. Scale bars, $300 \mu \mathrm{m}$.
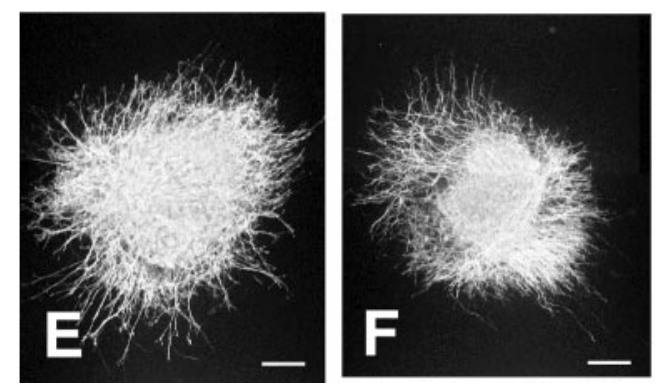

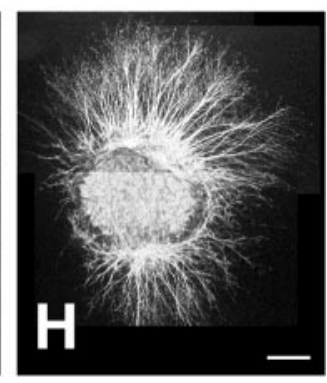

lated in the Matrigel (Fig. 4D). The outgrowth was significantly less in the heat-treated medium conditioned by telencephalic cells $\left(0.23 \pm 0.005 \mathrm{~mm}^{2} ; n=9\right)$ than in the medium conditioned by anterior tectal cells $(55 \% ; p<0.0001)$ with respect to the total area covered with the axonal bundles (see Fig. $6 B$ ). The DRG axons grew well in the heat-treated medium conditioned by telencephalic cells (Fig. 4H).

\section{A factor inhibiting the outgrowth of retinal axons in a fraction of peripheral membrane molecules from the telencephalon}

To further inspect the selective inhibition of axonal outgrowth, membrane fractions were prepared from the anterior tecta and telencephalons, and their effects on the retinal outgrowth were examined. The retinal axons grew well in media with the E8 anterior tectal membranes (Fig. 5B); however, they did not grow in media with the E8 telencephalic membranes (Fig. 5C). The retinal outgrowth was significantly less in the medium with telencephalic membranes than in the medium with anterior tectal membranes with respect to the total area covered with axonal bundles $\left[0.05 \pm 0.008 \mathrm{~mm}^{2}\right.$ with the $\mathrm{E} 8$ telencephalic membranes $(n=12) ; 0.27 \pm 0.04 \mathrm{~mm}^{2}$ with the $\mathrm{E} 8$ anterior tectal membranes $(n=12) ; p<0.0001$ ] (Fig. 6C). The retinal axons also did not grow in media with the E13 telencephalic membranes [0.08 \pm $0.015 \mathrm{~mm}^{2}(n=12)$ ] (Fig. $\left.6 C\right)$. In contrast, the DRG axons grew well in the media with either anterior tectal or telencephalic membranes (Fig. 5E,F).

To examine whether the inhibitory factor adheres to surfaces of the telencephalic membranes, a fraction of peripheral membrane molecules was prepared with the phase-partitioning method using Triton X-114, and its effect was investigated on the retinal outgrowth. The retinal axons did not grow in media with the peripheral membrane molecules from the E8 telencephalon $[0.13 \pm$ $0.012 \mathrm{~mm}^{2}(n=12) ; p<0.002$; the total area covered with axonal bundles with the E8 telencephalic peripheral membrane molecules] (Figs. 5H, 6C), although they grew in media with the peripheral membrane molecules from the E8 anterior tecta (Fig. $5 G)$. The DRG axons grew well in the media with peripheral membrane molecules from either the anterior tecta or telencephalon (Fig. $5 J, K$ ).

\section{Destruction of the factor inhibiting the outgrowth of retinal axons by chondroitinase $A B C$}

To further characterize the factor that selectively inhibits the retinal outgrowth, the E8 telencephalic membranes were treated with heat or enzymes, and their effects on the retinal outgrowth were examined. The retinal axons did not grow in media with the heat-treated telencephalic membranes $\left(100^{\circ} \mathrm{C}, 5 \mathrm{~min}\right)[0.05 \pm$ $0.013 \mathrm{~mm}^{2}(n=12) ; p<0.0001$; with respect to the area covered with axonal bundles] (Fig. $6 C$ ). The retinal axons also did not grow in media with the telencephalic membranes that had been treated with keratanase $\left(0.5 \mathrm{U} / \mathrm{mg}\right.$ protein at $37^{\circ} \mathrm{C}$ for $1 \mathrm{hr}$ ) (data not shown). In contrast, in media with the telencephalic membranes that had been treated with chondroitinase ABC $(0.5 \mathrm{U} / \mathrm{mg}$ protein at $37^{\circ} \mathrm{C}$ for $1 \mathrm{hr}$ ), the retinal axons grew profusely [0.31 \pm $0.040 \mathrm{~mm}^{2}(n=12) ; p=0.43$; with respect to the area covered with axonal bundles] (Figs. 5I, 6C). The DRG axons grew well in the media with the telencephalic membranes that had been treated with heat, keratanase (data not shown), or chondroitinase ABC (Fig. 5L)

\section{Aberrant routing of the retinal axons at the diencephalotelencephalic boundary after enzymatic removal of chondroitin sulfate from embryonic brain in ovo}

To understand the biological relevance of CS-GAG as the factor that selectively inhibits retinal outgrowth, the distribution of CS-GAG was examined immunohistochemically in the brains of E7 chickens with an anti-CS-GAG antibody (Fig. $7 A, C$ ). In the telencephalon, CS-GAG immunoreactivity was intense in general, especially on the pial side, except that it was moderate in the ventricular zone. In the diencephalon, the optic tract situated below the pia was labeled, whereas the ventricular zone was moderately labeled. In contrast, the SOT wiring between telencephalon and diencephalon was not labeled by the anti-CS-GAG antibody. Between the pial surface and SOT, there was a layer of cells that were intensely labeled. Over the thinnest part of the positive cells, there existed a sharp groove between the telencephalon and diencephalon on the pial side, which is referred to as a boundary between the diencephalon and telencephalon. In the neural retina, a gradient of CS-GAG distribution was con- 

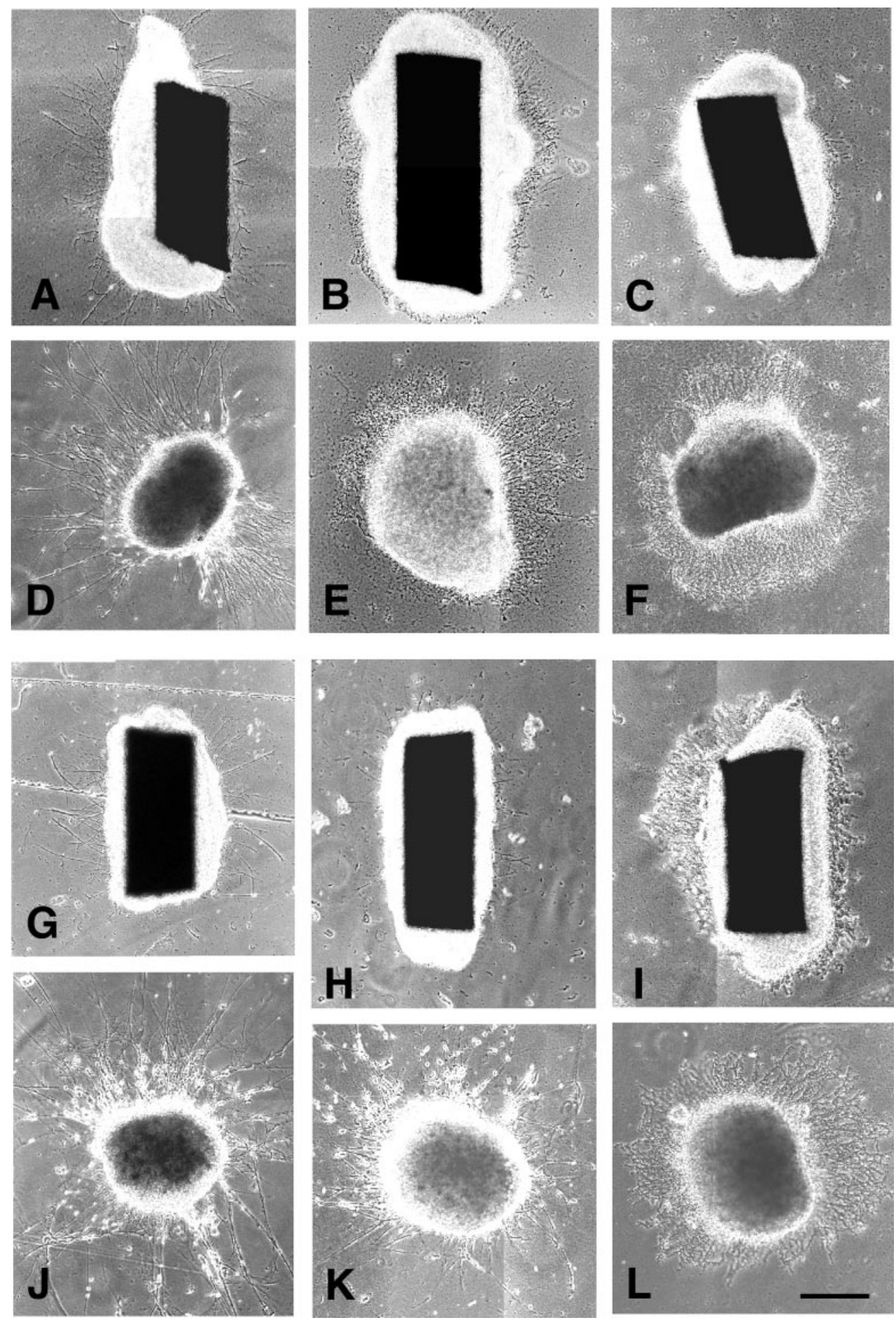

firmed; it was intense in the peripheral retina and was less intense in the central retina (data not shown) (Snow et al., 1991; Ring et al., 1995). The distribution of CS-GAG was the same between the normal brains and the brains in which a solution of the chondroitinase $\mathrm{ABC}$ that had been inactivated by heat $\left(100^{\circ} \mathrm{C}, 5 \mathrm{~min}\right)$ had been injected.

The solution of chondroitinase $\mathrm{ABC}(5 \mu \mathrm{l}, 1 \mu \mathrm{U} / \mu \mathrm{l})$ was injected into the right lateral ventricle of the E6 chickens. To verify the removal of CS-GAG by the injection, their brains were fixed on E7, sectioned, and stained with anti-CS-GAG antibody.
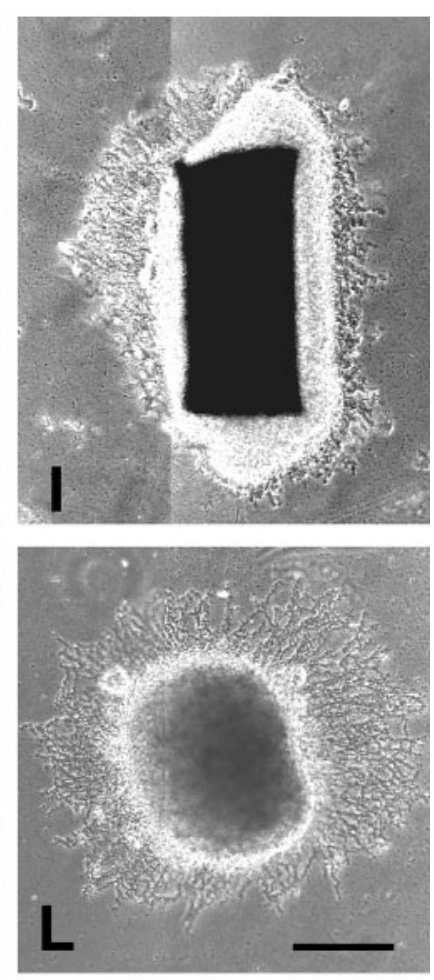
central retina (Fig. $7 E, F)$.
Figure 5. Axonal outgrowth in the media with the membrane fractions or peripheral membrane molecules. The retinal $(A-C, G-I)$ and DRG $(D-F$, $J-L)$ explants are cultured in the $\mathrm{F}-12$ minimum medium $(A, D)$, in the medium with the anterior tectal membranes $(B, E)$, in the medium with $\mathrm{E} 8$ telencephalic membranes $(C, F)$, in the medium with peripheral membrane molecules extracted from E8 anterior tectal membranes $(G, J)$, in the medium with peripheral membrane molecules extracted from E8 telencephalic membranes $(H, K)$, and in the medium with E8 telencephalic membranes treated with chondroitinase $\operatorname{ABC}(I, L)$. Scale bar, $300 \mu \mathrm{m}$.

The CS-GAG immunoreactivity was greatly reduced bilaterally in the telencephalon, diencephalon, and tectum. Around the diencephalotelencephalic boundary, the CS-GAG immunoreactivity was lost at the layer of cells between the optic tract and SOT (Fig. 7B). The sections were double-stained with DAPI; their cytoarchitecture was preserved (Fig. $7 D$ ). On the other hand, the gradient of CS-GAG distribution was retained in the neural retina even after the enzymatic treatment; CS-GAG immunoreactivity was intense in the peripheral retina and less intense in the 
$(\mathrm{mm})$
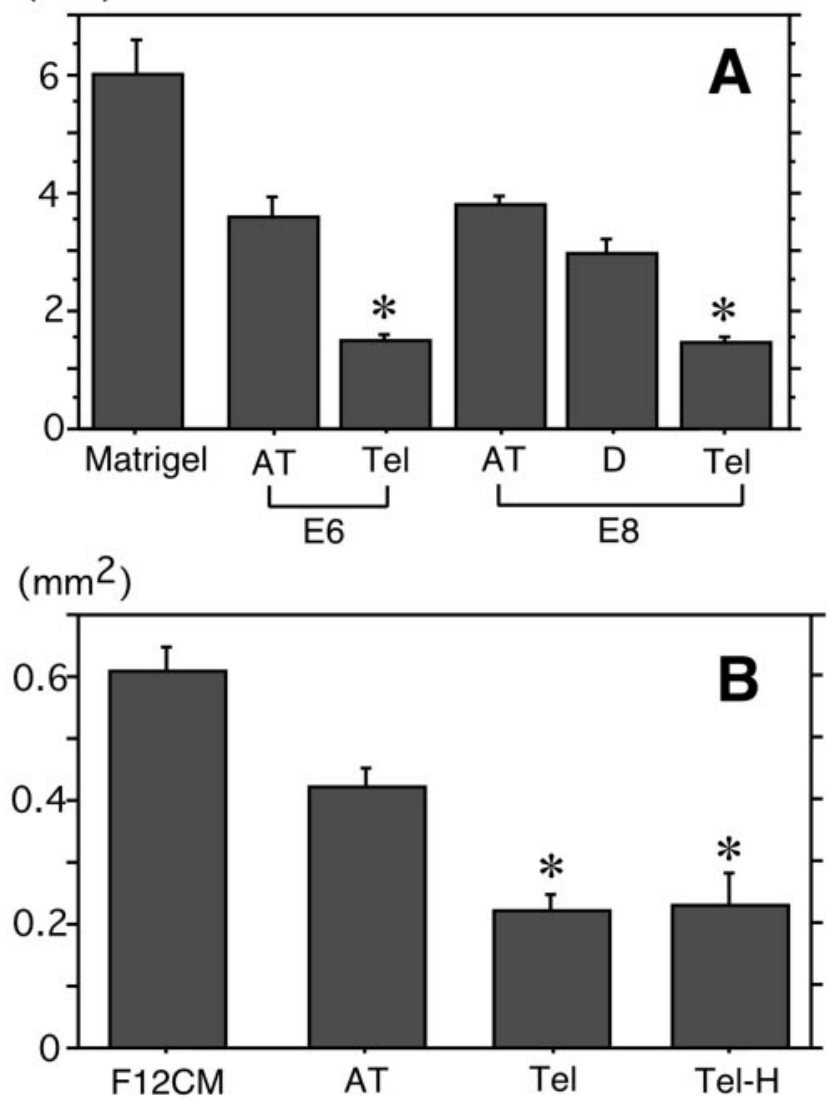

$\left(\mathrm{mm}^{2}\right)$

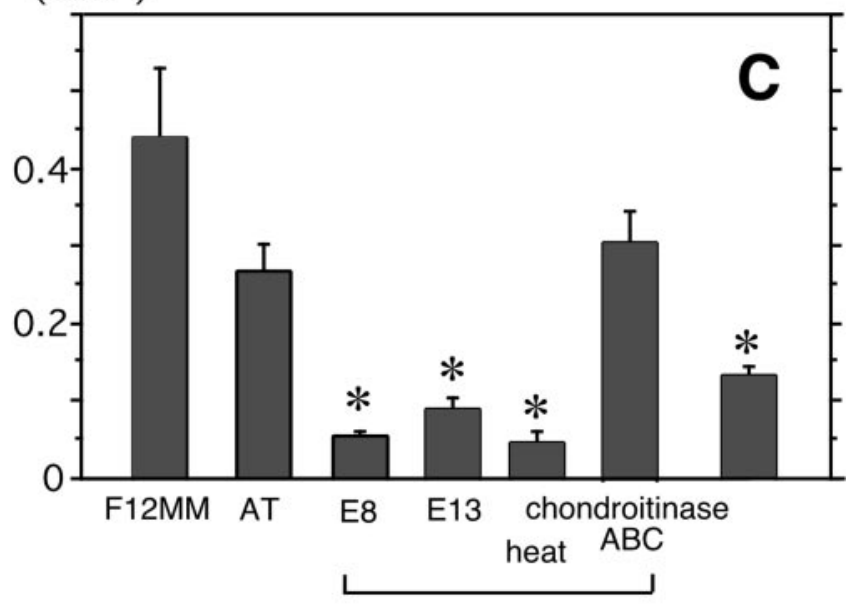

Tel

PM-Tel

Figure 6. Outgrowth of the retinal axons in the experiments in vitro. A, The diameters of axonal halos are shown on the substrates in the ryomen chambers. Matrigel, The Nuclepore filter coated with the Matrigel solution; $A T-E 6$, the E6 anterior tectal substrate; Tel-E6, the E6 telencephalic substrate; $A T-E 8$, the E8 anterior tectal substrate; $D-E 8$, the E8 diencephalic substrate; $T e l-E 8$, the E8 telencephalic substrate. $B$, The total areas covered with the axonal bundles are shown in the conditioned media. $F 12 C M$, The F-12 culture medium; $A T$, the medium conditioned by the E8 anterior tectal cells; Tel, the medium conditioned by the E8 telencephalic cells; $\mathrm{Tel}-\mathrm{H}$, the heat-treated medium conditioned by the E8 telencephalic cells. $C$, The total areas covered with the axonal bundles are shown in the media with the membrane fractions or peripheral membrane molecules. $F 12 M M$, The F-12 minimum medium; $A T$, the medium with the E8 anterior tectal membranes; $E 8$ - $T e l$, the medium with the E8 telencephalic membranes; E13-Tel, the medium with the E13 telencephalic membranes;
To examine the effects of the CS-GAG removal on pathway formation of the retinal axons, they were anterogradely labeled with HRP after injection of chondroitinase ABC or the heatinactivated enzyme. By the whole-mount observation, it was shown in the embryos injected with the chondroitinase $\mathrm{ABC}$ that an anterior margin of the optic tract seemed to be neither sharp nor straight, but to curve convexly toward the telencephalon (14 cases of the 16 embryos injected with the chondroitinase ABC, $87.5 \%$ ) (pictures not shown). This curving was seldom seen in the control embryos (two cases of the 15 embryos injected with the heat-inactivated enzyme, $13.3 \%$ ). Those embryos were subjected to the histological examinations; in the embryos injected with the chondroitinase $\mathrm{ABC}$, the retinal axons were situated over the anterior groove above the thin layer of cells on the SOT, which is likely to cause this groove to become shallow (Fig. $7 H, J$ ). To quantify the aberrant anterior shift of the optic tract, it was measured that the distances between the most anteriorly situated retinal axon and the groove above the thin layer of cells on the SOT, the diencephalotelencephalic boundary. In the control embryos injected with the heat-inactivated enzyme, the retinal axon was situated at $28.5 \pm 13.4 \mu \mathrm{m}(n=8)$ anterior to the boundary (Figs. $7 G, I, 8)$. In contrast, the retinal axon was situated at $78.9 \pm$ $7.7 \mu \mathrm{m}(n=8)$ anterior to the boundary in the embryos injected with the chondroitinase ABC (Fig. 8), which was significantly different $(p<0.01)$.

\section{DISCUSSION}

We found that the retinal outgrowth was selectively inhibited by the telencephalic cells in vitro. The responsible factor for the selective inhibition was found in the fraction of peripheral membrane molecules of the telencephalon. Because the inhibitory effect was destroyed by chondroitinase $\mathrm{ABC}$ but not by the heat treatment, this inhibition was attributable to carbohydrate chains of CSPGs (CS-GAG) adhering to the telencephalic membranes. To understand the function of the telencephalic CSPGs on pathfinding of the retinal axons in vivo, CS-GAG was removed from the embryonic brains by intraventricular injection of chondroitinase ABC. The removal of CS-GAG resulted in an anterior enlargement of the optic tract.

\section{Technical considerations}

The ryomen chamber assay has been developed previously for investigating the formation of the topographic map in the retinotectal projection (Ichijo and Bonhoeffer, 1998). Cellular substrates mimicked the in vivo situation more closely in the ryomen chamber than in the conventional cultures; this might be because the cells are packed between the filter and a gel matrix at a high density with a sufficient supply of gases, which allows them to locally interact with each other. As can be seen in Figure 2, the telencephalic substrates were composed of a variety of cellular processes derived from neurons and immature glia but not from mature glia; thus, the composition of the substrates reflected the cellular components of the telencephalon during the early stage of development. Although the ryomen chamber assay is a sensitive method for investigating the neuron-target interactions, this model is not necessarily feasible for biochemical approaches

$\leftarrow$

heat-Tel, the medium with the E8 telencephalic membranes treated with heat; chondroitinase $A B C$-Tel, the medium with the E8 telencephalic membranes treated with chondroitinase ABC; $P M-T e l$, the medium with the peripheral membrane molecules from the E8 telencephalon. Asterisks indicate the significant differences from the ATs in each graph $(p<0.01)$. 

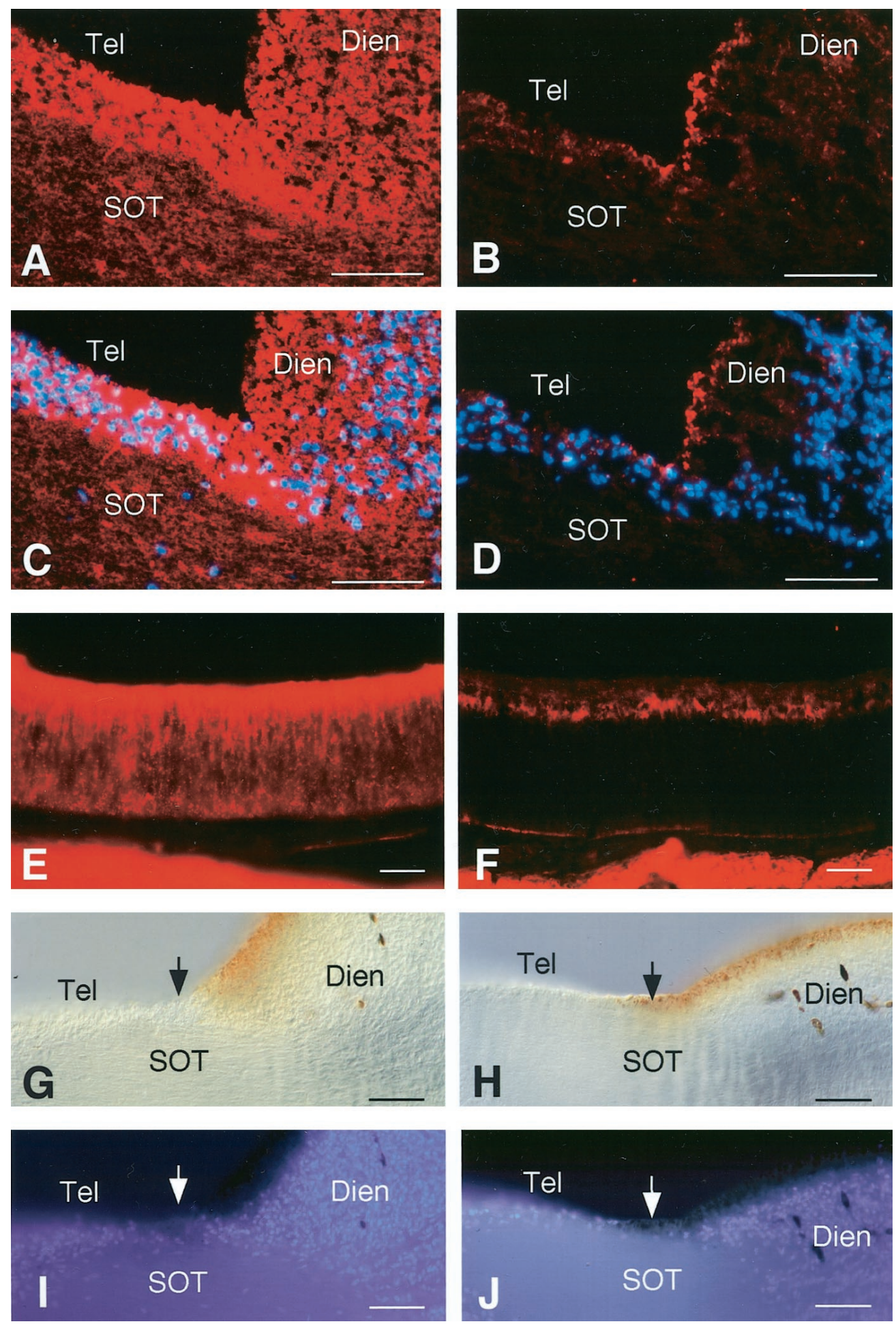

Figure 7. The enzymatic removal of CS-GAG and its effect on the trajectories of the retinal axons. $A$, Distribution of CS-GAG is immunofluorescently shown on a horizontal section around the diencephalotelencephalic boundary in the control E7 chicken treated with the inactivated chondroitinase ABC. $C$, The cytoarchitecture of the junctional region is shown by double-staining with DAPI. $B$, Removal of CS-GAG and its residual distribution are shown in the E7 chicken treated with chondroitinase ABC. $D$, The cytoarchitecture is shown by double-staining with DAPI. The distribution of CS-GAG is not influenced in the neural retina in the $\mathrm{E} 7$ chicken treated with chondroitinase $\mathrm{ABC}$; the immunofluorescent signal is intense in the peripheral retina $(E)$, although it is weak in the central retina $(F)$. $G$, The retinal axons labeled with HRP are shown on a horizontal section around the diencephalotelencephalic boundary in the E7 embryo treated with the inactivated chondroitinase ABC. I, The cytoarchitecture is shown with DAPI; the retinal axons are situated posterior to the groove (arrows) above the thin layer of cells on the SOT. $H$, The retinal axons labeled with HRP are shown in the E7 chicken treated with chondroitinase ABC. $J$, The cytoarchitecture is shown with DAPI; the retinal axons are situated over the anterior groove (arrows) above the thin layer of cells on the SOT. Dien, Diencephalon; Tel, telencephalon; SOT, the supraoptic tract. The anterior sides are left $(A-D, G-J)$. The exposures in the photographs are the same between $A$ and $B, C$ and $D, E$ and $F, G$ and $H$, and $I$ and $J$. Scale bars: $A-D, 25 \mu \mathrm{m} ; E-J, 50 \mu \mathrm{m}$.

because of the small scale of the culture. This limitation was complemented by the retinal explant culture with membrane fractions; it enabled us to characterize the factor with the phasepartitioning method and to destroy the factor with chondroitinase $\mathrm{ABC}$.

\section{Carbohydrate chains of CSPGs on the telencephalic membranes are the factor inhibiting the outgrowth of the retinal axons}

The telencephalic effect on the retinal outgrowth was observed during the stages in which the retinal axons find their path on the diencephalon, in the telencephalic substrates on E6 and E8, or in the telencephalic membranes on E8 and E13 (Figs. 3, 5, 6A, C). Moreover, the retinal axons ran on the boundary between the telencephalon and diencephalon (Fig. 1); it is probable that their growth cones or side branches sense the surface of telencephalic cells or their extracellular matrix. These results in vitro suggest that the telencephalic cells operate during the pathway formation of the retinal axons.

In the ryomen chambers, the outgrow th of the retinal axons was selectively inhibited by the telencephalic substrates (Fig. $3 A, B$ ); 


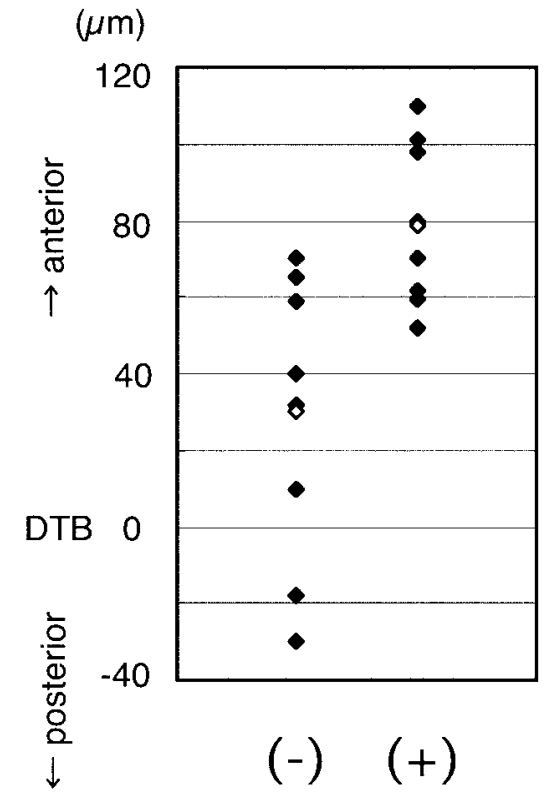

Figure 8. Anterior enlargement of the retinal trajectories at the diencephalotelencephalic boundary by the enzymatic removal of CS-GAG. Relative positions of the most anteriorly situated retinal axons to the groove above the thin layer of cells on the SOT, the diencephalotelencephalic boundary, are plotted as filled diamonds in the embryos treated with the inactivated enzyme $(-)$ or the chondroitinase $\mathrm{ABC}(+)$. The mean values are also indicated (open diamonds). DTB, The diencephalotelencephalic boundary.

this effect was seen in the medium conditioned by the telencephalic cells (Fig. 4C). The telencephalic membranes inhibited the retinal outgrowth selectively but not the DRG outgrowth at the same concentration (Fig. 5C,F); furthermore, this effect was recovered in the fraction of peripheral membrane molecules from the telencephalon (Fig. 5H). Therefore, the responsible factor is thought to be secreted and adhere to the surface of the telencephalic membranes or extracellular matrix. The treatment of telencephalic membranes with chondroitinase ABC completely destroyed their effect (Figs. 5I, 6C); thus, it is likely to result from CS-GAGs bound to a heterogeneous set of core proteins in CSPGs.

The CSPGs are involved in promotion and inhibition of axonal growth (Maeda and Noda, 1996; Garwood et al., 1999). Although the promotion and inhibition are seemingly contradictory effects, they are attributable to the heterogeneity of the CSPGs because of variations in the core proteins and carbohydrate chains and also because of differences in sensitivity between different types of neurons. One of their roles has been identified as an inhibitor of axonal outgrowth during development and injury (Silver, 1994; Schwab and Bartholdi, 1996). The inhibitory effects seem to be attributable to their carbohydrate chains (CS-GAG) for the retinal outgrowth in the periphery of the retina (Brittis et al., 1992), the optic chiasm (Chung et al., 2000b), and dorsal midline of the optic tectum (Snow et al., 1990; Jhaveri, 1993), and for the DRG outgrowth in the roof plate of the spinal cord (Snow et al., 1990). On the other hand, the enzymatic removal of CS-GAGs does not eliminate their inhibitory effect, which results from their core proteins or other types of carbohydrate chains on their core proteins (Oohira et al., 1991; Dou and Levine, 1994; Maeda and Noda, 1996; Niederost et al., 1999). Furthermore, the CSPGs are likely to modulate the intercellular communications controlling the pathfinding of the retinal axons because it has been reported that the CSPGs bind to some of the cell adhesion molecules and growth factors (Grumet et al., 1993; Friedlander et al., 1994; Emerling and Lander, 1996; Milev et al., 1996; Sakurai et al., 1996; Anderson et al., 1998; Soussi-Yanicostas et al., 1998). In the present study, however, the inhibitory effect on axonal outgrowth does not seem to be caused by the core proteins of CSPGs or the proteinaceous factors associated with CSPGs because the effect was stable even after the treatment with heat $\left(100^{\circ} \mathrm{C}, 5 \mathrm{~min}\right)$.

The effect of the telencephalic membranes was dose dependent; high concentrations of the telencephalic membranes inhibited the outgrowth of the DRG neurites as well as the retinal axons (data not shown). The retinal axons are, therefore, more sensitive to CSPGs than the DRG neurites as shown by Snow et al. (1991). In addition, higher concentrations of even the anterior tectal membranes inhibited the outgrowth of both the retinal and DRG axons (data not shown). The immunohistochemical examinations did not show that distribution of CS-GAG was specific in the telencephalon, but the CS-GAG was broadly distributed with variations in the signal intensity; the immunoreactivity was intense in telencephalon and moderate in the diencephalon and tectum (Fig. 7A). Although it is difficult to elucidate local concentrations of CS-GAG, the density of CS-GAG in the telencephalic membranes is likely to be higher than that of the anterior tectal membranes; the high content of the CS-GAG might cause the selective inhibition of retinal outgrowth by the telencephalic substrates, telencephalic membranes, and the fraction of peripheral membrane molecules from telencephalon in the cultures. In the normal embryos, the CS-GAG was intensely distributed on the pial side of the telencephalon. At the diencephalotelencephalic boundary, the CS-GAG immunoreactivity was intense at the thin layer of cells between the optic tract and SOT (Fig. 7A), suggesting that this layer separates the optic tract from the SOT.

It has been suggested that the CSPGs are thought to function not only in pathfinding but also in differentiation (Brittis and Silver, 1994; Nichol et al., 1994; Canoll et al., 1996; Maeda and Noda, 1996). The abundant distribution of CS-GAG indicates that the CSPGs are involved with various steps in pathfinding and differentiation; the spatial pattern of CS-GAG distribution would not necessarily have to be specific in the telencephalon or at the demarcation of the diencephalotelencephalic boundary.

\section{Involvement of CS-GAG in pathfinding of retinal axons around the diencephalotelencephalic boundary}

Injection of chondroitinase $\mathrm{ABC}$ into the right lateral ventricle removed CS-GAG from telencephalon, diencephalon, and tectum, although their cytoarchitecture was retained (Fig. 7B,D). On the other hand, the CS-GAG was not removed in the eyeball; the graded distribution of CS-GAG was kept in the retinas (Fig. $7 E, F$ ) (Chung et al., 2000b); thus, the removal of CS-GAG was not likely to influence differentiation of the retinal ganglion cells (Brittis and Silver, 1994) but was likely to affect the local environment around the retinal axons. The enzymatic treatment did not only lower the concentrations of the CS-GAG around the retinal pathway but also cancelled the spatial pattern of its distribution. Immunoreactivity against CS-GAG was lost in the layer of cells between the optic tract and SOT and on the pial side of the telencephalon (Fig. $7 B$ ). Although the enzymatic treatment was effective, residual expression of CS-GAG was observed sporadically, which might be attributable to either incomplete removal or recovered deposits because of the gradual decay of the enzymatic activity and its transient action. By transiently lowering 
the local concentration and erasing the spatial pattern of CSGAG distribution, the enzymatic treatment seemed to affect pathfinding of a fraction of the retinal axons that ran around the diencephalotelencephalic boundary on their way to the tectum.

The enzymatic removal of CS-GAG induced the anterior enlargement of the optic tract beyond the groove between the telencephalon and diencephalon, causing this groove to become shallow (Figs. 7H,J, 8). The retinal axons are likely to be released from outgrowth inhibition and allowed to enter foreign territories. The results indicate that the mechanism inhibiting the invasion of the retinal axons into the telencephalon is, at least in part, likely to be attributable to the function of CS-GAG, which delimits the anterior border of the optic tract. It is suggested that the telencephalic cells prevent the retinal axons from aberrantly invading the anterior territory and restrict the retinal pathway to the tectum.

The enzymatic treatment seemingly induced the restricted effects on the retinal trajectory at the diencephalotelencephalic boundary, although the CS-GAGs were widely distributed in the normal embryos and they were homogenously removed in the experimental embryos. The antibody (CS-56) and the chondroitinase $\mathrm{ABC}$ used in this study do not discriminate types of the CS-GAGs but recognize the various types of the CS-GAGs; a specific type of CS-GAGs might cause the anterior delimitation of the retinal trajectory.

Several mutants in the zebrafish show retinal axons that invade the telencephalon (Karlstrom et al., 1996). There is a similarity between the effects of intraventricular injection of chondroitinase $\mathrm{ABC}$ and the phenotypes of these mutants, although the retinal axons enter the anterior territory less dramatically in the embryos treated with chondroitinase ABC than in the mutants, presumably because of the transient action of the enzyme. The CS-GAG might be involved in the phenotypes of the mutants, in which its receptor or intracellular signaling might be affected.

\section{REFERENCES}

Anderson RB, Key B (1999) Novel guidance cues during neuronal pathfinding in the early scaffold of axon tracts in the rostral brain. Development 126:1859-1868.

Anderson RB, Walz A, Holt CE, Key B (1998) Chondroitin sulfates modulate axon guidance in embryonic Xenopus brain. Dev Biol 202:235-243.

Brittis PA, Silver J (1994) Exogenous glycosaminoglycans induce complete inversion of retinal ganglion cell bodies and their axons within the retinal neuroepithelium. Proc Natl Acad Sci USA 91:7539-7542.

Brittis PA, Canning DR, Silver J (1992) Chondroitin sulfate as a regulator of neuronal patterning in the retina. Science 255:733-736.

Brusca JS, Radolf JD (1994) Isolation of integral membrane proteins by phase partitioning with Triton X-114. Methods Enzymol 228:182-193.

Canoll PD, Petanceska S, Schlessinger J, Musacchio JM (1996) Three forms of Rptp-Beta are differentially expressed during gliogenesis in the developing rat brain and during glial cell differentiation in culture. J Neurosci Res 44:199-215.

Chedotal A, Pourquie O, Sotelo C (1995) Initial tract formation in the brain of the chick embryo: selective expression of the BEN/SC1/DMGRASP cell adhesion molecule. Eur J Neurosci 7:198-212.

Chung KY, Shum DK, Chan SO (2000a) Expression of chondroitin sulfate proteoglycans in the chiasm of mouse embryos. J Comp Neurol 417:153-163.

Chung KY, Taylor JS, Shum DK, Chan SO (2000b) Axon routing at the optic chiasm after enzymatic removal of chondroitin sulfate in mouse embryos. Development 127:2673-2683.

Deiner MS, Sretavan DW (1999) Altered midline axon pathways and ectopic neurons in the developing hypothalamus of netrin-1- and DCCdeficient mice. J Neurosci 19:9900-9912.

Deiner MS, Kennedy TE, Fazeli A, Serafini T, Tessier-Lavigne M, Sretavan DW (1997) Netrin-1 and DCC mediate axon guidance locally at the optic disc: loss of function leads to optic nerve hypoplasia. Neuron 19:575-589.

Dingwell KS, Holt CE, Harris WA (2000) The multiple decisions made by growth cones of RGCs as they navigate from the retina to the tectum in Xenopus embryos. J Neurobiol 44:246-259.
Dou CL, Levine JM (1994) Inhibition of neurite growth by the NG2 chondroitin sulfate proteoglycan. J Neurosci 14:7616-7628.

Dutting D, Handwerker C, Drescher U (1999) Topographic targeting and pathfinding errors of retinal axons following overexpression of ephrinA ligands on retinal ganglion cell axons. Dev Biol 216:297-311.

Easter SS, Ross LS, Frankfurter A (1993) Initial tract formation in the mouse brain. J Neurosci 13:285-299.

Emerling DE, Lander AD (1996) Inhibitors and promoters of thalamic neuron adhesion and outgrowth in embryonic neocortex: functional association with chondroitin sulfate. Neuron 17:1089-1100.

Erskine L, Williams SE, Brose K, Kidd T, Rachel RA, Goodman CS, Tessier-Lavigne M, Mason CA (2000) Retinal ganglion cell axon guidance in the mouse optic chiasm: expression and function of robos and slits. J Neurosci 20:4975-4982.

Friedlander DR, Milev P, Karthikeyan L, Margolis RK, Margolis RU, Grumet M (1994) The neuronal chondroitin sulfate proteoglycan neurocan binds to the neural cell adhesion molecules Ng-CAM/L1/NILE and N-CAM, and inhibits neuronal adhesion and neurite outgrowth. J Cell Biol 125:669-680.

Fujisawa H (1987) Mode of growth of retinal axons within the tectum of Xenopus tadpoles, and implications in the ordered neuronal connection between the retina and the tectum. J Comp Neurol 260:127-139.

Garwood J, Schnadelbach O, Clement A, Schutte K, Bach A, Faissner A (1999) DSD-1-proteoglycan is the mouse homolog of phosphacan and displays opposing effects on neurite outgrowth dependent on neuronal lineage. J Neurosci 19:3888-3899.

Goodman CS (1996) Mechanisms and molecules that control growth cone guidance. Annu Rev Neurosci 19:341-377.

Grumet M, Flaccus A, Margolis RU (1993) Functional characterization of chondroitin sulfate proteoglycans of brain: interactions with neurons and neural cell adhesion molecules. J Cell Biol 120:815-824.

Guillery RW, Mason CA, Taylor JS (1995) Developmental determinants at the mammalian optic chiasm. J Neurosci 15:4727-4737.

Halfter W, Newgreen DF, Sauter J, Schwarz U (1983) Oriented axon outgrowth from avian embryonic retinae in culture. Dev Biol 95:56-64.

Holt CE, Harris WA (1993) Position, guidance, and mapping in the developing visual system. J Neurobiol 24:1400-1422.

Ichijo H, Bonhoeffer F (1998) Differential withdrawal of retinal axons induced by a secreted factor. J Neurosci 18:5008-5018.

Jhaveri S (1993) Midline glia of the tectum: a barrier for developing retinal axons. Perspect Dev Neurobiol 1:237-243.

Karlstrom RO, Trowe T, Klostermann S, Baier H, Brand M, Crawford AD, Grunewald B, Haffter P, Hoffmann H, Meyer SU, Muller BK Richter S, van Eeden FJ, Nusslein-Volhard C, Bonhoeffer F (1996) Zebrafish mutations affecting retinotectal axon pathfinding. Development 123:427-438

Levy D, Bluzat A, Seigneuret M, Rigaud JL (1990) A systematic study of liposome and proteoliposome reconstitution involving Bio-Beadmediated Triton X-100 removal. Biochim Biophys Acta 1025:179-190.

Maeda N, Noda M (1996) 6b4 Proteoglycan/phosphacan is a repulsive substratum but promotes morphological differentiation of cortical neurons. Development 122:647-658.

Marcus RC, Matthews GA, Gale NW, Yancopoulos GD, Mason CA (2000) Axon guidance in the mouse optic chiasm: retinal neurite inhibition by ephrin "A"-expressing hypothalamic cells in vitro. Dev Biol 221:132-147

Mason CA, Sretavan DW (1997) Glia, neurons, and axon pathfinding during optic chiasm development. Curr Opin Neurobiol 7:647-653.

Mastick GS, Easter SS (1996) Initial organization of neurons and tracts in the embryonic mouse fore- and midbrain. Dev Biol 173:79-94.

Mey J, Thanos S (2000) Development of the visual system of the chick. I. Cell differentiation and histogenesis. Brain Res Rev 32:343-379.

Milev P, Maurel P, Haring M, Margolis RK, Margolis RU (1996) Tag1/axonin-1 is a high-affinity ligand of neurocan, phosphacan/proteintyrosine phosphatase-zeta/beta, and N-CAM. J Biol Chem 271:15716-15723.

Nakagawa S, Brennan C, Johnson KG, Shewan D, Harris WA, Holt CE (2000) Ephrin-B regulates the Ipsilateral routing of retinal axons at the optic chiasm. Neuron 25:599-610.

Nichol KA, Everett AW, Schulz M, Bennett MR (1994) Retinal ganglion cell survival in vitro maintained by a chondroitin sulfate proteoglycan from the superior colliculus carrying the HNK-1 epitope. J Neurosci Res 37:623-632.

Niclou SP, Jia L, Raper JA (2000) Slit2 is a repellent for retinal ganglion cell axons. J Neurosci 20:4962-4974.

Niederost BP, Zimmermann DR, Schwab ME, Bandtlow CE (1999) Bovine CNS myelin contains neurite growth-inhibitory activity associated with chondroitin sulfate proteoglycans. J Neurosci 19:8979-8989.

Nomura KH, Kobayashi R, Hirabayashi Y, Fujisue-Sakai M, Mizuguch S, Nomura K (1998) Involvement of blood-group-B-active trisaccharides in $\mathrm{Ca}^{2+}$-dependent cell-cell adhesion in the Xenopus blastula. Dev Genes Evol 208:9-18.

Ohta K, Tannahill D, Yoshida K, Johnson AR, Cook GM, Keynes RJ (1999) Embryonic lens repels retinal ganglion cell axons. Dev Biol 211:124-132. 
Oohira A, Matsui F, Katoh-Semba R (1991) Inhibitory effects of brain chondroitin sulfate proteoglycans on neurite outgrowth from PC12D cells. J Neurosci 11:822-827.

Rager G, Morino P, Schnitzer J, Sonderegger P (1996) Expression of the axonal cell adhesion molecules axonin-1 and Ng-CAM during the development of the chick retinotectal system. J Comp Neurol 365:594-609.

Ring C, Lemmon V, Halfter W (1995) Two chondroitin sulfate proteoglycans differentially expressed in the developing chick visual system. Dev Biol 168:11-27.

Ringstedt T, Braisted JE, Brose K, Kidd T, Goodman C, Tessier-Lavigne M, O'Leary DDM (2000) Slit inhibition of retinal axon growth and its role in retinal axon pathfinding and innervation patterns in the diencephalon. J Neurosci 20:4983-4991.

Sakurai T, Friedlander DR, Grumet M (1996) Expression of polypeptide variants of receptor-type protein tyrosine phosphatase beta: the secreted form, phosphacan, increases dramatically during embryonic development and modulates glial cell behavior in vitro. J Neurosci Res 43:694-706.

Schwab ME, Bartholdi D (1996) Degeneration and regeneration of axons in the lesioned spinal cord. Physiol Rev 76:319-370.

Silver J (1994) Inhibitory molecules in development and regeneration. J Neurol 242:S22-S24.

Silver J, Poston M, Rutishauser U (1987) Axon pathway boundaries in the developing brain. I. Cellular and molecular determinants that separate the optic and olfactory projections. J Neurosci 7:2264-2272.

Snow DM, Steindler DA, Silver J (1990) Molecular and cellular characterization of the glial roof plate of the spinal cord and optic tectum: a possible role for a proteoglycan in the development of an axon barrier. Dev Biol 138:359-376.
Snow DM, Watanabe M, Letourneau PC, Silver J (1991) A chondroitin sulfate proteoglycan may influence the direction of retinal ganglion cell outgrowth. Development 113:1473-1485.

Soussi-Yanicostas N, Faivre-Sarrailh C, Hardelin JP, Levilliers J, Rougon G, Petit C (1998) Anosmin-1 underlying the X chromosome-linked Kallmann syndrome is an adhesion molecule that can modulate neurite growth in a cell-type specific manner. J Cell Sci 111:2953-2965.

Taylor JS (1991) The early development of the frog retinotectal projection. Development Suppl 2:95-104.

Tessier-Lavigne M, Goodman CS (1996) The molecular biology of axon guidance. Science 274:1123-1133.

Thanos S, Fujisawa H, Bonhoeffer F (1984) Elimination of ipsilateral retinotectal projections in mono-ophthalmic chick embryos. Neurosci Lett 44:143-148.

Trowe T, Klostermann S, Baier H, Granato M, Crawford AD, Grunewald B, Hoffmann H, Karlstrom RO, Meyer SU, Muller B, Richter S, Nusslein-Volhard C, Bonhoeffer F (1996) Mutations disrupting the ordering and topographic mapping of axons in the retinotectal projection of the zebrafish, Danio rerio. Development 123:439-450.

Tuttle R, Braisted JE, Richards LJ, O'Leary DD (1998) Retinal axon guidance by region-specific cues in diencephalon. Development 125:791-801.

Walz A, McFarlane S, Brickman YG, Nurcombe V, Bartlett PF, Holt CE (1997) Essential role of heparan sulfates in axon navigation and targeting in the developing visual system. Development 124:2421-2430.

Wilson SW, Ross LS, Parrett T, Easter Jr SS (1990) The development of a simple scaffold of axon tracts in the brain of the embryonic zebrafish, Brachydanio rerio. Development 108:121-145. 